KARL JANSEN-WINKELN

\title{
Die Plünderung der Königsgräber des Neuen Reiches ${ }^{1}$
}

1. Als die neuzeitliche Erforschung der Gräber im Tal der Könige einsetzte, wurden im allgemeinen nur noch ganz geringe Reste der ursprünglichen Ausstattung angetroffen, v.a. natürlich viele der Steinsarkophage. Der größte Teil der Königsmumien und ein Teil der Holzsärge sind dagegen in zwei Sammelverstecken gefunden worden, eines davon im Tal selbst, eine Seitenkammer im Grab Amenophis' II. (KV 35), das andere in den Bergen bei Deir el-Bahari, die berühmte Cachette von Deir el-Bahari (T'T 320). Im Grab Amenophis' II. ${ }^{2}$ fanden sich die Mumien von Amenophis II. und III., Thutmosis IV., Merenptah, Sethos' II., Siptah, Ramses IV.-VI. und, vielleicht, Sethnacht, z. T. noch in ihren Holzsärgen, dazu einige Familienmitglieder und Anonyme, bei denen es sich gleichfalls um nähere Angehörige handeln dürfte. In der Cachette von Deir el-Bahari ${ }^{3}$ waren Amosis, Amenophis I., Thutmosis I.-III., Sethos I., Ramses II.-III. und IX., dazu gleichfalls einige Familienangehörige bzw. Anonyme. Außerdem wurden hier einige Mitglieder der Königsfamilie aus dem Übergang von der 17. zur 18. Dynastie gefunden, und zum dritten wurde diese Höhle auch als Sammelgrab der Hohenpriesterfamilie der 21. Dynastie genutzt.

Wann die Umbettungen erfolgt sind, dafür gibt es zumindest für die eine größere Gruppe in Deir el-Bahari Hinweise: Auf einigen der dort befindlichen Mumien und Särgen finden sich hieratische datierte Vermerke über verschiedene Umbettungen bzw. Wiederbestattungen ${ }^{4}$. Diese Vermerke reichen von einem Jahr 6 unter Herihor bis zum 10. Jahr Siamuns. Man kann ihnen also entnehmen, daß sich diese Aktionen praktisch über die gesamte 21. Dynastie erstreckten.

2. Die noch bis vor kurzem nahezu ausnahmslos vertretene Meinung ist nun die, daß die Königsgräber am Ende des Neuen Reiches oder sogar auch noch danach von Räuberbanden geplündert worden seien und die Hohenpriester der 21. Dynastie nur noch die Reste geborgen hätten. Diese Rettungsaktionen der Priester werden in der Literatur z. T. bewegend dargestellt. Gestützt auf die verschiedenen Umbettungen v. a. Sethos' I. und Ramses' II. wird geschildert, wie die Priester die Mumien, ,in abenteuerlicher Flucht vor den Banden von Grab zu Grab geschleppt" hätten ${ }^{5}$.

Nun gibt es für Grabräubereien in Theben ja auch reichlich Zeugnisse. Die zu diesem Thema erhaltenen Papyri ${ }^{6}$ stammen fast ausschließlich aus einer Serie von Untersuchungen, die in den

\footnotetext{
${ }^{1}$ Abkürzungen nach Lexikon der Ägyptologie, Bd. VII, p. XIVff. Außerdem Reeves, Valley = C. N. Reeves, Valley of the Kings; the decline of a royal necropolis, Studies in Egyptology, London 1990; Wente, Letters = E. F. Wente, Letters from Ancient Egypt, Atlanta 1990.

${ }^{2}$ S. Reeves, Valley, $192 \mathrm{ff}$.

${ }^{3}$ Op. cit., p. $183 \mathrm{ff}$.

${ }^{4}$ S. die Zusammenstellungen bei Reeves, op. cit., p. $225 \mathrm{ff}$. und Kitchen, Third Interm. Period, $₫ 379 \mathrm{ff}$.

${ }^{5}$ S. E. Brunner-Traut, Die Alten Ägypter, Stuttgart 1974, 241. Ähnlich sonst oft.

${ }^{6}$ Zusammengestellt bei Peet, Tomb Robberies; dazu id., The Mayer Papyri A \& B, London 1920 und J. Capart/A.H. Gardiner/B. van de Walle, „New Light on the Ramesside Tomb-Robberies“, JEA 22, 1936 , 169-193.
} 
Jahren 16-18 Ramses' IX. ${ }^{7}$ und in den Jahren 19-20 Ramses' XI. geführt worden sind. Bei der ersten Serie handelt es sich um Gerichtsprotokolle, Listen von Dieben und sichergestelltem Beutegut sowie um einen kompletten Bericht über eine Inspektion von Gräbern und andere damit zusammenhängende Vorfälle. Es geht um Diebstähle aus Gräbern sowie von Tempelausstattung ${ }^{8}$, und man erfährt, daß zahlreiche Privatgräber ausgeraubt worden sind, ebenso ein Königsgrab der 17. Dynastie (Sbk-m-s3.f II.). Von diesem letzteren Vorfall geben die Diebe selbst im Verhör eine detaillierte Beschreibung ${ }^{9}$. Bei der Inspektion ${ }^{10}$ werden 10 Königsgräber aus der Zeit vom Mittleren Reich bis zum Beginn der 18. Dynastie (bis zu Amenophis I.) überprüft und alle intakt befunden, mit der einzigen bereits erwähnten Ausnahme aus der 17. Dynastie, wo man die Täter ja auch schon hatte. Das Tal der Könige wird nicht überprüft, offenbar, weil das nicht nötig war. Die Gräber im Tal der Königinnen werden dagegen überprüft und intakt befunden ${ }^{11}$.

Bei der zweiten Serie von Untersuchungen, die etwa 30 Jahre später stattfanden (hier hat man nur Verhörprotokolle und Listen der Verdächtigen ${ }^{12}$ ) gibt es Diebstähle aus Tempeln und Palästen $^{13}$ und aus Gräbern von Königinnen und Privatleuten.

Beide Diebstahlserien fallen in eine Zeit innerer Unruhen bzw. Kriege: Die zweite, spätere, ist gleichzeitig mit der Revolte des Vizekönigs von Nubien, Panehsi, gegen den Hohenpriester und den König ${ }^{14}$. Bei der ersten, früheren, weiß man nicht so genau, was vorgefallen ist, aber auf jeden Fall gibt es gerade aus der Zeit, in der die Diebstähle passiert sein müssen, etwa von Jahr 8-15 Ramses' IX., zahlreiche, leider nur fragmentarische Erwähnungen von Einfällen von "Ausländern“ (b3stjw), speziell von Libyern ${ }^{15}$. Diese Zeit ist also gleichfalls sehr unsicher gewesen.

Zwischen diesen beiden Serien scheint es aber, wie C. Aldred ausgeführt hat ${ }^{16}$, keine größeren Vorfälle mehr gegeben zu haben: Während einem der Verhöre unter Ramses XI. sagt ein Angeklagter, er habe gesehen, wie unter Ramses IX. die Gräberdiebe bestraft worden seien, und deshalb sei es doch ganz unwahrscheinlich, daß er Ähnliches getan habe. Da er also auf die erste Serie der Grabräuberprozesse hinweist, die etwa 30 Jahre zurückliegt, wird man schließen dürfen, daß dazwischen nichts Ernsthaftes vorgefallen ist ${ }^{17}$.

\footnotetext{
7 Überliefert in pAbbott, pBM 10053, pBM 10054, pBM 10068, pAmherst/Leopold II und Teilen des "Nekropolentagebuchs" in Turin.

${ }^{8}$ In pBM 10054, rto., 3,7-17.

${ }^{9}$ Im pAmherst/Leopold II.

${ }^{10} \mathrm{Im}$ pAbbott beschrieben.

${ }^{11}$ Allerdings wird zu einem etwas späteren Zeitpunkt (Jahr 17) das Grab der Isis im Tal der Königinnen beraubt vorgefunden, wie das Nekropolentagebuch berichtet, s. Peet, Tomb Robberies, p. 76-7; Kitchen, Ram. Inscr., VI, 579.

${ }^{12}$ pBM 10052; pMayer A; pBM 10383; pBM 10403; „Abbott Dockets“.

${ }^{13} \mathrm{pBM} 10383,2,4:$ n 3 sb3w $n$ p3 $\operatorname{pr} n \operatorname{pr}^{-{ }^{2}}$ ?.

${ }^{14}$ S. ZÄS 119, 1992, $26 \mathrm{ff}$.

${ }^{15}$ S. CAH ${ }^{3}$, Bd. II, 2, Cambridge 1975, 616-9; D. Valbelle, Les ouvriers de la tombe, BdE 96, 1985, p. 208-9. Im einzelnen s. Kitchen, Ram. Inscr., VI, 609,5-6 (Jahr 8); 637-8 (Jahr 10; 11); 563-4 (Jahr 13); 643 (Jahr 15); vgl. auch 687-8 (Jahr 3 Ramses' X.). Vgl. auch Biblische Notizen 71, 1994, 86-91.

${ }^{16}$ In Fs Fairman, p. 92.

${ }^{17}$ Bei den Verhören aus dem Jahr 9 Ramses' XI. in pBM 10053 vso. geht es ausschließlich um Diebstähle aus Tempeln. Ob die „šrmt-Liste“ des pBM 10068 vso. aus dem Jahr 12 Ramses’ XI. (bzw. später) etwas mit den Grabräubereien zu tun hat, wie Aldred angenommen hat (op. cit., p. 94), ist fraglich, s. J. J. Janssen in AoF 19, 1992, 21.
} 
3. Es ist nun auffallend, daß nirgends in diesem recht umfangreichen Dossier die Gräber im Tal der Könige erwähnt werden ${ }^{18}$. Auch aus früherer Zeit gibt es nur sehr spärliche Andeutungen über mögliche oder tatsächliche Beraubungen:

- Wie aus einem Graffito in seinem Grab hervorgeht ${ }^{19}$, ist die Bestattung Thutmosis' IV. im Jahr 8 Haremhabs erneuert worden. Den Grund dafür erfährt man nicht, aber das Nächstliegende ist natürlich, an eine Wiederherstellung nach einem Grabraub zu denken.

- Ob das Grab des Tutanchamun kurz nach der Bestattung beraubt wurde, ist sehr zweifelhaft. Früher war dies die allgemein akzeptierte Ansicht, aber R. Krauss hat in einem Aufsatz von 1986 überzeugend dagegen argumentiert ${ }^{20}$. Wie auch immer, auf jeden Fall kann es kein Diebstahl im großen Stil gewesen sein, wenn überhaupt, müßte es sich um einige Kleinigkeiten gehandelt haben.

- Gleichfalls sehr fraglich ist, ob die Gräber von Maiherperi (KV 36) und Tuyu/Yuya (KV 46) im eigentlichen Sinne, d.h. nachdem sie endgültig verschlossen wurden, beraubt worden sind, wie Reeves dies annimmt ${ }^{21}$. Diese relativ geringen Diebstähle könnten auch während des Begräbnisses bzw. der Vorbereitungen dazu geschehen $\operatorname{sein}^{22}$, wie das ja für das Begräbnis Sethos' II. bezeugt ist, s. u.

- Auch andere Fälle, in denen Reeves Grabräubereien während des Neuen Reiches vermutet, sind unsicher oder unwahrscheinlich: Ganz aus dem Spiel lassen sollte man die Gräber der Königsfamilie der Amarnazeit, also das des Eje (WV 23) und KV 55 $5^{23}$, wo eine offizielle Öffnung im Rahmen der damnatio memoriae mehr Wahrscheinlichkeit hat als Reeves' Rekonstruktion der Ereignisse ${ }^{24}$.

Die Tatsache, daß das thebanische Graffito Nr. 1860 aus dem 8. Jahr Ramses VI. über dem Eingang von KV 35 steht, muß keineswegs bedeuten, daß sich das darin berichtete bn $(r) p^{3}$ $b r$ auf dieses Grab bezieht, wie Reeves vorschlägt ${ }^{25}$, das ist sogar sehr unwahrscheinlich, da es dem Gebrauch des Ausdrucks $p_{3}^{3}$ br widerspräche ${ }^{26}$.

Bei KV 12, einem undekorierten Grab, ist sogar unklar, ob es im Neuen Reich jemals belegt war. Über „Beraubungen“"27 läßt sich hier wirklich nichts sagen.

Auch eine angebliche Plünderung von KV 60 durch die Nekropolenarbeiter während der Arbeiten an KV 19, wie es Reeves ${ }^{28}$ im Anschluß an Carter ${ }^{29}$ vorschlägt, ist Spekulation.

- Sicher ist dagegen, daß während der Streiks am Ende der Regierung Ramses' III. einmal der Eingang des Grabs Ramses’ II. mutwillig beschädigt wird ${ }^{30}$ und daß der berüchtigte Vorarbeiter Paneb sogar während der Beisetzung Sethos' II. etwas stiehlt ${ }^{31}$, aber das sind eher Lappalien.

${ }^{18}$ Zum pMayer B, dessen genaue Datierung nicht klar ist, s. u.

${ }^{19}$ S. Urk IV, 2170-1.

${ }^{20}$ MDOG 118, $165 \mathrm{ff}$. Die Ausführungen von Reeves, Valley, p. $63 \mathrm{ff}$. sind mir nicht recht nachvollziehbar.

${ }^{21}$ Op. cit., p. $143 \mathrm{ff}$; $149 \mathrm{ff}$.

${ }^{22}$ Vgl. auch BiOr 49, 1992, 713.

${ }^{23}$ Reeves, Valley, p. $72 ; 44$.

${ }^{24}$ Vgl. auch Antiquity 64, 1990, 924; BiOr 49, 1992, 710.

${ }^{25}$ Op. cit., p. 222 , n. 139.

${ }^{26}$ S. Černý, Community, p. 17.

${ }^{27}$ Vgl. Reeves, op. cit., p. 130-1.

28 Ibid., p. 139.

29 ASAE 4, 1903, 177.

${ }^{30}$ RAD, p. 57, 10-12.

${ }^{31}$ JEA 15, 1929, pl. 42, Z. 4 ff. 
- Im pMayer B wird geschildert ${ }^{32}$, wie eine Bande von 5 Räubern in das Grab Ramses' VI. eindringt und Bronze- und Kupfergeräte sowie Textilien stiehlt. Bis zum eigentlichen Begräbnis sind die Diebe also wohl nicht vorgedrungen. Daß ausgerechnet das Grab Ramses' VI. (KV 9) beraubt werden konnte, dürfte nicht zufällig sein: Bei seiner Ausschachtung wurde versehentlich ein älteres Grab (KV 12) angeschnitten, durch das die Diebe offenbar eingedrungen $\operatorname{sind}^{33}$. Dieses ältere Grab ist undekoriert und war vielleicht gar nicht belegt, so daß man bei einer Kontrolle der Siegel das Eindringen nicht bemerken konnte. Im Grab Ramses' VI. gibt es ein Graffito aus dem Jahr 9 Ramses' IX. mit einem Vermerk über eine Inspektion $^{34}$, die sich auf den im pMayer B beschriebenen Vorfall beziehen dürfte.

Von diesem besonderen Fall abgesehen kommt als ernsthafter Kandidat für eine wirkliche Beraubung, ein gewaltsames Eindringen nach der Bestattung, vor dem Ende der Ramessidenzeit nur das Grab Thutmosis' IV. in Frage. Sollte es geplündert worden sein, wäre dies mutmaßlich in der Amarnazeit passiert, also ebenfalls in einer innenpolitisch turbulenten Zeit, wo zudem die Nekropolenarbeiter (zumindest z. T.) wohl gar nicht in Theben beschäftigt waren ${ }^{35}$.

4. Der Grund für diese weitgehende Unversehrtheit des Tals ist natürlich seine leichte Bewachbarkeit ${ }^{36}$. In der 20. Dynastie erfährt man also - von dem einen Fall des Grabes Ramses' VI. abgesehen, und auch dort wird ja das eigentliche Begräbnis nicht gestört - nichts von Plünderungen durch Räuberbanden im Tal der Könige. Auch für die 21. Dynastie ist das ganz unwahrscheinlich: In dieser Zeit stand Oberägypten unter der Herrschaft der Hohenpriester des Amun, die gleichzeitig - besser gesagt, in erster Linie - militärische Oberbefehlshaber waren. Der Hohepriester residierte aller Wahrscheinlichkeit nach auf der Westseite in Medinet $\mathrm{Habu}^{37}$. Ich halte es für undenkbar, daß er es zuließ, daß sich unweit seiner Residenz Räuberbanden ungestört herumtreiben und die Königsgräber berauben konnten, die doch mühelos zu bewachen waren, oder daß seine Beamten gar, wie dem oben (\$2) zitierten Szenario $\mathrm{zu}$ entnehmen ist, vor ihnen fliehen mußten. Wir wissen zwar nicht allzuviel über die Geschichte der 21. Dynastie, aber allem Anschein nach hat es sich um ein recht straffes Militärregime gehandelt; derartige Zustände sind sicher nicht anzunehmen.

Dazu kommt noch etwas anderes, worauf schon Aldred hingewiesen hatte ${ }^{38}$ : Bei den Räuberbanden aus den Grabräuberpapyri handelt es sich jeweils nur um eine Handvoll Leute, die bei Nacht ausziehen und sich dann auch noch häufig über die Beute streiten. Eine Plünderung der Schätze eines Königsgrabs, v.a. der Begräbnisstätte, hätte aber eine Arbeit in ganz anderen Dimensionen bedeutet, wenn man nur an die tonnenschweren Sarkophage denkt. Mit kleinen Banden war da nicht viel auszurichten. Auch die reine Masse an Edelmetall wäre gar nicht absetzbar gewesen, ohne sich sofort verdächtig zu machen.

\footnotetext{
${ }^{32}$ S. Peet, The Mayer Papyri A \& B, London 1920, p. 19-20; Tafel am Ende.

${ }^{33}$ S. Reeves, op. cit., p. $130-1$.

${ }^{34}$ W. Spiegelberg, Ägytische und andere Graffiti aus der thebanischen Nekropolis, Heidelberg 1921, p. 92.

${ }^{35}$ Vgl. Černý, Community, p. 50-2.

${ }^{36}$ Die auch damit zusammenhängt, daß alles nahe beieinander liegt. Ein gewaltsames Öffnen eines Grabes hätte schon durch die damit verbundene Geräuschentwicklung auch bei nur sehr oberflächlicher Bewachung sofort auffallen müssen.

${ }^{37}$ S. LÄ III, 1267. Außer den Inschriften Pajnedjems I. in Medinet Habu (s. PM II², 523, Mitte) deuten noch andere Indizien darauf, z. B. die Erstürmung von Medinet Habu anläßlich des „Krieges des Hohenpriesters“ kurz vor Einführung der Wḥm-mswt-Ära.

${ }^{38}$ Fs. Fairman, p. 96.
} 
5. Auf die Unhaltbarkeit der bisherigen Vorstellungen hat zuerst C. Aldred in seinem schon zitierten Aufsatz von 1979 hingewiesen ${ }^{39}$. Auch er hält eine Beraubung der Königsgräber in der 21. Dynastie für ganz ausgeschlossen. Da wir aber - wie gesehen - aus dem Zeitraum unmittelbar davor keinerlei Anzeichen für eine Strafverfolgung von Diebstählen aus Königsgräbern haben, kommt Aldred auf folgende Idee: Einige Zeugenaussagen in den Grabräuberpapyri spielen auf einen Krieg oder Bürgerkrieg an, der zwischen den Jahren 17 und 19 Ramses' XI., also unmittelbar vor der 2. Serie der Prozesse stattgefunden haben muß, und in dem der Gouverneur von Nubien, Panehsi, der damals zugleich der eigentliche Machthaber in Theben war, bis nach Unterägypten vordringt und erst dann von königstreuen (?) Truppen zurückgeschlagen wird ${ }^{40}$. Wenige Jahre später (aber noch unter Ramses XI.) führt der General Pianch dann in Nubien Krieg gegen Panehsi. Er ist also vollständig aus Ägypten verdrängt worden, kann sich aber offensichtlich in Nubien halten, denn dort hat man sein Grab gefunden ${ }^{41}$. Aldred schlägt nun vor ${ }^{42}$, daß es Panehsi und seine Truppen gewesen sein könnten, die auf dem Rückzug die Königsgräber plünderten. In diesem Fall wäre es verständlich, daß bei den Grabräuberprozessen von den Königsgräbern keine Rede ist, denn Täter und Beute wären ja dann längst außer Reichweite gewesen. Zudem wären auch die technischen Schwierigkeiten, vor die ein Königsgrab kleinere Räuberbanden gestellt hätte, nicht vorhanden gewesen, wenn eben eine ganze Armee zur Verfügung stand. Die Theorie Aldreds wäre also zunächst einmal durchaus eine Möglichkeit, die Dinge zu erklären ${ }^{43}$; dennoch wird in den meisten danach erschienenen Darstellungen an der These von den („zivilen“) Räuberbanden festgehalten.

6. Es gibt aber noch eine zweite Möglichkeit, die zuerst E. Hornung angedeutet hat: Nach dem Neuen Reich habe man eingesehen, daß die Gräber im Tal der Könige auf die Dauer nicht zu schützen waren, und man begann deshalb, die Mumien umzubetten: „Die Möglichkeit besteht, daß man die Öffnung der Gräber und Umbettung der Mumien dazu benutzte, die wertvollen Beigaben offiziell sicherzustellen, um sie nicht in die Hände von einheimischen Grabräubern fallen zu lassen. Mit dem Ende des Neuen Reiches waren ja auch die nubischen Goldminen versiegt, der Import aus Asien stockte, und für die neue Staatsführung lag die Versuchung nahe, das nach den Grabräuberakten immer noch unberührte Tal der Könige als nahe, bequeme Schatzkammer für Edelmetalle und Halbedelsteine zu nutzen. “ ${ }^{44}$

Eben diese Möglichkeit wird neuerdings - offenbar unabhängig von Hornung - auch von N. Reeves in seiner zusammenfassenden Arbeit über das Tal der Könige von 1990 vertreten $^{45}$. Ihm zufolge ist die thebanische Regierung durch die häufigen Grabräubereien am Ende der 20. Dynastie - auch wenn das Tal der Könige in der Hauptsache nicht betroffen war - doch dazu gebracht worden, die Begräbnisse einerseits zusammenzulegen, um sie besser bewachen zu können, andrerseits alle Wertgegenstände zu entfernen, und dies mit zwei Zielen: Zum einen sollen die Begräbnisse für Räuber unattraktiv werden, zum anderen aus ökonomischen Gründen, um nach Verlust der asiatischen und nubischen Länder noch eine Einnahmequelle zu haben. Reeves argumentiert also ganz ähnlich wie Hornung. Darüber hinaus zieht er als

\footnotetext{
39 „More Light on the Ramesside Tomb Robberies“ in: Fs Fairman, p. 92-99.

${ }^{40} \mathrm{Vgl}$. jetzt Z̈̈S 119, 1992, $26 \mathrm{ff}$.

${ }^{41}$ Vgl. G. Steindorff, Aniba, II, Glückstadt 1937, p. 240-1; Taf. 29 c.

${ }^{42}$ Op. cit., p. 96.

${ }^{43}$ Sie erschien mir selbst auch bis vor kurzem noch am wahrscheinlichsten, s. ZÄS 119, 1992, 31.

44 Tal der Könige. Die Ruhestätte der Pharaonen, Zürich/München 1982, p. 78.

45 Valley, p. 276-8.
} 
Stütze für seine Ansicht auch eine Stelle aus den „Late Ramesside Letters“ heran. Der Brief, um den es geht ${ }^{46}$, ist von den beiden Vorarbeitern und dem Schreiber Butehamun an den General und Hohenpriester Pianch gerichtet, und darin werden auch mehrere Passagen aus einem vorherigen Schreiben des Pianch selbst zitiert. Eine davon lautet: ${ }^{47}$ „Sieh, du hast uns geschrieben mit den Worten, Öffnet ein Grab von den alten ${ }^{48}$ Gräbern und bewacht sein Siegel, bis ich komme. " Das kann nur bedeuten, daß er daran geht, ein unangetastetes Grab zu öffnen, und darum sieht Reeves hierin einen entscheidenden Hinweis darauf, daß die Gräber in Wirklichkeit von der Administration und nicht von Räubern ausgeräumt wurden ${ }^{49}$.

7. Im folgenden möchte ich versuchen, deutlich zu machen, daß Hornung und Reeves mit ihrer Deutung grundsätzlich richtig liegen, daß also die Königsgräber des Neuen Reiches nicht von Räubern, sondern von Staats wegen ausgeräumt worden sind.

Wenn man sich den Brief, dem Reeves die zitierte Stelle entnommen hat, einmal im ganzen ansieht, hat man den Eindruck, daß er noch mehr entsprechende Hinweise enthält ${ }^{50}$ :

Von den einleitenden Segenswünschen abgesehen kann man den Brief in zwei Teile gliedern, jeweils auch äußerlich durch einleitendes $b n^{c} \underline{d} d \mathbf{b z w}$. kejj $\underline{d} d$ markiert. Der erste Teil $(44,16-47,1)$ ist in diesem Zusammenhang nicht so wichtig. Er scheint eine Entschuldigung dafür zu enthalten, daß die Arbeiter einen Befehl des Pianch, irgendwelche Stoffe zu bringen, nicht schnell genug befolgt haben, weil sie inzwischen ein zweiter Brief erreicht hatte mit einem weiteren Befehl, der offenbar die Ausführung des ersten verzögerte, und zudem gelang es ihnen nicht rechtzeitig, ein Boot zum Übersetzen zu bekommen, so daß Pianch bereits abgereist war und Thutmose ihm mit den Stoffen hinterhergeschickt werden mußte. Interessant an diesem ersten Teil des Briefes ist in jedem Fall, daß darin deutlich die große Angst der Arbeiter vor dem General zu spüren ist. Das geht nicht zuletzt aus dem Schlußabschnitt hervor, der aus lauter Beteuerungen ihres Gehorsams besteht, und wird besonders klar in rto.24 (LRL, 46,6-7), wo gesagt wird, daß Thutmose (vor Angst) fast gestorben wäre ( $j w . f b p r\langle b r\rangle m w t$ $n . f)$, als er die Stadt erreichte und hörte, daß Pianch schon abgereist war ${ }^{51}$.

Der zweite Teil $(47,1-48,4)$ ist aufschlußreicher:

„Eine andere Mitteilung von den Arbeitern der großen erhabenen Nekropole für unseren Herrn: Wir haben alle Dinge gehört, über die unser Herr uns geschrieben hat. Das, was uns unser Herr geschrieben hat mit den Worten: , Geht und führt mir eine Arbeit ( aus, zu der ihr noch nie ausgezogen seid ( $w^{c} \operatorname{shn} j w$ bwpw.tn $\left.s^{m} n f^{c} n\right)^{52}$, und sucht nach ihr,

${ }^{46}$ pBM 10375, s. LRL, Nr. 28, p. 44-48.

47 LRL, 47,12-3.

${ }^{48}$ Reeves, op. cit, p. 277 übersetzt ,a tomb amongst the foremost tombs (or, the tombs of the ancestors)“.

${ }^{49}$ Der Ansicht von Reeves hat sich inzwischen auch J. Taylor angeschlossen, vgl. „Aspects of the History of the Valley of the Kings in the Third Intermediate Period" in: C. N. Reeves (ed.), After Tut ankhamun; Research and excavation in the Royal Necropolis at Thebes, London 1992, p. 186-206. Vgl. auch A. Dodson, GM 132, $1993,28$.

${ }^{50}$ Übersetzungen dieses Briefes bei Wente, LRL, p. 59-65; id., Letters, p. 194-5; vgl. auch S. Groll, RdE 26, 1974, 170-1 und J. J. Janssen, BiOr 25, 1968, 37, n. 4.

${ }^{51}$ S. Černý, Community, p. 364 und zu mwt + dativus incommodi F. Hintze, Untersuchungen zu Stil und Sprache neuägyptischer Erzählungen, Berlin 1950/52, p. 88-90. Wente, LRL, p. 60 bezieht das „sterben“ auf das Boot, und J. Frandsen, An Outline of the Late Egyptian Verbal System, Kopenhagen 1974, p. 22 (27) ebenso wie H. Satzinger, Neuägyaptische Studien, Wien 1976, p. 245 sind ihm darin gefolgt. In seiner neuesten Übersetzung (Letters, p. 194) versteht aber auch Wente die Stelle im Sinne Černýs.

${ }^{52}$ Die Übersetzung Wentes in LRL (p. 61: „a commission for which you have never yet gone") ist zweifellos korrekt, nicht seine neue in Letters (p. 195: ,a certain [building] commission ... if you have not already gotten to it"), die auf Groll (s. Anm. 50) zurückgeht. Nach dem indeterminierten w s sḥn kann der folgende Umstandssatz 
bis ich zu euch komme; - so sprach unser Herr - , was ist denn geschehen ${ }^{53}$ (mit) dem, das ihr kennt, wo ihr schon wart? Laßt es (liegen), rührt es nicht an! - So sprach unser Herr: Dieser Schreiber, der hier an unserer Spitze war - und er ist es (ja), der (Rat?) geben (kann), denn er kannte eine Aufsichts(person), die ein großer Mann war, und sein Vater hat es [= die von diesem erhaltene Information] bestätigt - er ist bei dir. Sobald er auch vor uns Zeugnis ablegt [= uns sein Wissen mitteilt], brauchen wir 10-20 Tage, indem er täglich die Aufsicht versieht $(?)^{54}$, bis er findet.

Siehe, Du hast geschrieben mit den Worten: , Öfnet ein Grab von den alten Gräbern und bewacht sein Siegel, bis ich komme.' So sprach unser Herr. Wir führen Aufträge aus. Wir werden es dich (unberührt) gelassen und vorbereitet finden lassen - das, was wir kennen. (Aber) du solltest uns den Nekropolenschreiber Tjaroi schicken, damit er kommt und die Aufsicht für uns versieht, denn wir gehen umher (??), indem wir uns verlaufen ${ }^{55}$ und nicht wissen, worauf wir treten können" (folgen abschließende Grüße).

Man kann dem folgendes entnehmen:

Die Arbeiter werden von Pianch zu einer Aufgabe abgeordnet, die irgendetwas mit einem Bauwerk (Det. $\sqsubset$ ) zu tun haben muß und die sie vorher nie verrichtet haben. Es kann sich also nicht um das Anlegen neuer Gräber handeln. Diese Arbeit ist außerdem erst zu suchen, das Bauwerk muß also versteckt liegen. Im zweiten Zitat aus dem Brief des Pianch erfährt man, daß er sich nach den Orten erkundigt, die sie schon aufgesucht haben, wo sie schon waren: Sie sollen sie unberührt lassen, wobei auch hier zweifellos gemeint ist: Bis ich komme. Es geht also zunächst nur darum, bestimmte versteckt liegende Bauwerke aufzuspüren und dann auf Pianch zu warten. Um diese Aufgabe zu bewältigen, wäre es nützlich, so legen die Arbeiter dar, ihren alten Schreiber Thutmose dabei zu haben, der jetzt mit Pianch in Nubien ist: Er hat wichtige Informationen über das, was sie tun sollen, die er einerseits von einer hochgestellten Person $\left(r m \underline{t}^{c_{3}}\right)$ hat, die offenbar damit zu tun hatte (vielleicht der Bürgermeister

nur als „unechter“ Relativsatz verstanden werden, nicht als Konditionalsatz. Außerdem zeigt der unbestimmte Artikel ja auch deutlich, daß es hier nicht etwa um einen bestimmten Auftrag geht, der nur noch nicht ausgeführt wurde; es handelt sich um eine ganz neue Art von Arbeit.

${ }^{53} j$ rj.tw. $f$ jb verstehe ich als (wörtl.) ,es ist gemacht worden, was“ ( $j b$ als Apposition zu $f$ ) $=$,was ist geschehen ". Die Phrase ist mehrfach in den Grabräuberakten belegt: pBM 10052, 4,17; pMayer A, 3,26-4,1; 6,15-6; 9,2; pBM 10383, 1,5, dort meist als unwillige Frage „was ist (denn schon, denn eigentlich) geschehen, was soll schon passiert sein" derjenigen Angeklagten, die sich dumm stellen. Eine unwillige Frage scheint auch hier vorzuliegen, allerdings nicht, weil Pianch sich dumm stellt, sondern weil er mißtrauisch ist.

${ }^{54}$ hij (WB III, 37,2) ist ein sehr problematisches Wort. Außer an den drei Stellen in diesem Brief ist es (nur in neuägyptischen Texten) belegt in Amenemope, 14,19; 24,17; pBologna 1086, IV,13 (ZÄS 65, 1930, 92); pAnastasi V, 26,4 (LEM, 71,8) und Kitchen, Ram. Inscr., VI, 7,6. Es bezeichnet z. T. ganz deutlich Personen: In unserem Brief (47,8-9) folgt auf $w^{c}$ bij die Qualifikation jw. $m \mathrm{rmt}^{c^{c}}{ }^{3}$. In pAnastasi V, 26,4 hat man $n^{3} b_{j j} n M_{\underline{d}} 3_{3} w b^{c} n^{3} j . s n$ sḥnw qnw, in Kitchen, Ram. Inscr. VI, 7,6 hjj prj $3 s$.... In all diesen Fällen kann es sich nur um Personen handeln, ebenso wohl in den Belegen im Amenemope. Ob in dem Satz jw t3j.f hjj ḥr dd in pBologna 1086 dasselbe Wort vorliegt, ist fraglich, ebenso, ob dort eine Person, eine Behörde (so WB) oder ein Schriftstück gemeint ist (so Groll in RdE 26, 171). Jedenfalls kann es sich dem Zusammenhang nach bei den anderen Stellen in diesem Brief nicht um eine Person handeln: Thutmose wird ja gerade angefordert, weil er selbst Bescheid weiß. Dies zusammen mit der Tatsache, daß bij in keinem einzigen Fall ein Personendeterminativ hat, spricht dafür, daß es an sich ein Abstraktum „Aufsicht, Kontrolle“ o. ä. ist, das je nach Zusammenhang auch personalisiert werden kann. ptr $w^{c}$ bij könnte dann so etwas wie „Aufsicht ausüben, Kontrolle ausüben“ bedeuten. Die Überzeugung „marker", die Wente (Letters, p. 195) jetzt im Anschluß an Groll bevorzugt, paßt auf jeden Fall nicht zu den Stellen, wo es sich eindeutig um Personenbezeichnungen handelt.

${ }^{55}$ Oder ,indem wir uns (wieder) zurückziehen“? 
der Weststadt?), andrerseits von seinem Vater (und Amtsvorgänger). Wenn er ihnen sein Wissen mitteilt, können sie ihre Aufgabe schneller erledigen ${ }^{56}$.

Dann folgt das 3. Zitat aus dem Brief des Pianch, das schon Reeves herangezogen hatte und in dem deutlich ausgesprochen wird, welche Bauwerke gemeint sind: alte Gräber. Die Arbeiter versprechen, alles im Sinne des Pianch zu tun, das Grab versiegelt zu lassen(!) und zur eigentlichen Öffnung nur vorzubereiten, und verlangen dazu noch einmal nach Thutmose, denn offenbar ist die Arbeit nicht einfach und ungefährlich, und es bedarf genauer Kenntnisse von Eingeweihten, um zu wissen, „,worauf man die Füße setzen kann“. Auch das ist eigentlich recht eindeutig, es kann nur um alte Grabanlagen gehen.

Der ganze zweite Teil des Briefes handelt also von diesem Thema, anders verstanden ergibt sich kaum ein sinnvoller Zusammenhang.

8. Man fragt sich natürlich, ob die Korrespondenz zwischen dem General Pianch und den Nekropolenarbeitern nicht noch weitere Hinweise enthält. Zumindest in Brief Nr. 19 (pBibl. Nat. 196, I) ${ }^{57}$ wäre das möglich:

Hier erkundigt sich der General bei Thutmose nach der Angelegenheit irgendwelcher Leute der Nekropole, die den Libyern $(M \check{M} w s)$ Brot $\left.{ }^{(} q w\right)$ zu geben pflegen, woraufhin Thutmose ihnen das untersagt habe. Pianch befiehlt ihm nun, diejenigen, die das tun, zu beobachten und sie dann einer bestimmten Person zu überstellen ${ }^{58}$, damit er ihnen das für die $M s_{w} w s^{̌}$ bestimmte Brot wegnehmen kann.

$\breve{C}{ }^{\prime} y^{59}$ hat diesen Brief als Anweisung des Pianch gedeutet, die Libyer weiter mit Brot zu versorgen, aber das läßt sich ihm kaum entnehmen. Es scheint mir überhaupt sehr fraglich, ob es sich wirklich um Brot handelt; das wird doch sofort konsumiert und kann kaum nachträglich beschlagnahmt werden. In einem zu den Grabräuberakten gehörigen Papyrus (pBM 10052) wird " $q w$ „Brot" mehrfach ganz deutlich als Bezeichnung von Diebesbeute verwendet $\left(3,4 ; 6,19 ; 14,6 ; s ; p n^{c} q w\right.$ in 1,9 ; dieselbe Metapher auch in 6, 4), wie schon Peet festgestellt hat ${ }^{60}$. Hier könnte dieselbe Bedeutung von ${ }^{c} q w$ vorliegen, um so mehr, als die $M s^{r} w$ auch sonst als Quelle von Diebesgut bekannt $\operatorname{sind}^{61}$.

Die Interpretation dieses Falles (wenn es einer ist) hängt von der Datierung des Briefes ab: Gehört er in eine frühere Zeit der $w h ̣ m-m s w t-$ Ära, könnte es sich um Aktivitäten im Zusammenhang mit den Grabräubereien handeln, die in den Grabräuberakten berichtet werden. Gehört er in eine spätere Zeit (um das Jahr 10), ist er eher in den hier behandelten Zusammenhang zu stellen: Dann hätten wohl einige Nekropolenangestellte die von Pianch angeordneten Gräberöffnungen für eigene Geschäfte genutzt.

9. Diese Suche nach alten Gräbern, die Pianch in pBM 10375 anordnet, ist auch noch auf andere Weise dokumentiert: In den Bergen des thebanischen Westufers gibt es einige tausend

\footnotetext{
${ }^{56} \mathrm{Ob}$ die 10-20 Tage bedeuten, daß sie solange brauchen, um sich ein altes (Königs)Grab so zu präparieren, daß es leicht auszuräumen ist?

${ }^{57}$ LRL, 35; Wente, LRL, p. 52; id., Letters, p. 184.

${ }^{58} P_{3} w n$ dj in 35,6 ist genereller Singular und die pluralischen Pronomina .w müssen sich darauf beziehen, nicht auf ' $q w$, wie Wente annimmt, sonst ergibt sich kein vernünftiger Sinn: Wenn man die 'qw dem $3 b$ - $m n w$ übergibt, kann er sie doch selbst nicht mehr wegnehmen.

${ }^{59} \mathrm{CAH}^{3}, \mathrm{II}, 2$, p. 619.

${ }^{60}$ Tomb-Robberies; s. die Anmerkungen zu den jeweiligen Stellen.

${ }^{61}$ S. pMayer A, 8,14, wo ein Angeklagter $4 d b n$ Silber von ihnen erworben hat.
} 
Felsgraffiti; etwa 4000 sind veröffentlicht (die meisten natürlich nur Namen) ${ }^{62}$. Das scheint viel zu sein, ist aber doch so erstaunlich nicht, wenn man den großen Zeitraum bedenkt.

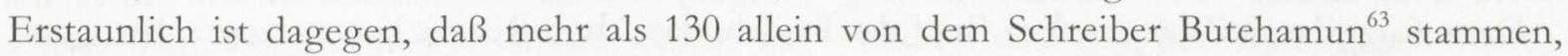
der auch den soeben besprochenen Brief verfaßt hat (und dazu kommt noch eine Reihe Graffiti seiner gleichzeitigen Kollegen). Auch diese Graffiti bestehen oft nur aus einem Namen, enthalten aber auch weitergehende Angaben: Mehrere datierte Graffiti besagen, daß „man kam, um die Berge zu sehen“ (Nr. 48; 51; 1001; 1021; 1393; 3492). Dieses „Sehen der Berge“ wird nun sicher keine touristische Vergnügung gewesen sein, sondern die Suche nach alten Gräbern, denn neue wurden ja in dieser Zeit gar nicht mehr angelegt. 2 Graffiti $\left(1359^{64} ; 2138^{65}\right)$ sagen auch explizit, daß man kam, „um das Tal zu öffnen“ und in einem weiteren (unmittelbar am Eingang von KV 42 aus der 18. Dynastie: 714) wird schließlich auch die Verbindung zum General Pianch hergestellt: Dort heißt es: „3. Sommermonat, Tag 23, Beginn der Arbeiten an diesem Grab $(s t h)$ durch die Nekropolentruppe, als der Schreiber Butehamun zur Stadt übersetzte, um die Ankunft des Generals nach Norden zu sehen. “ Im oben behandelten Brief hatte der General Pianch die Arbeiter angewiesen, auf ihn zu warten; es könnte hier durchaus eine Verbindung bestehen. Das mag zwar sehr kühn erscheinen, würde aber von den verfügbaren Daten her gut passen, da der Brief am Tag 29 des 1. Sommermonats geschrieben ist; es lägen also etwa 2 Monate dazwischen. Dennoch ist es natürlich sehr spekulativ, einen Zusammenhang zwischen Brief und Graffito zu sehen, wird doch im Datum das Jahr nicht genannt. Aber der Zusammenhang Nekropolentruppe - Arbeit an alten Gräbern - General Pianch ist sehr deutlich.

In einem weiteren Graffito aus dieser Zeit (Nr. 1282) über einem Grab (KV 49) wird die Anlieferung von größeren Mengen Stoffen registriert: Wie schon Reeves gesehen hat ${ }^{66}$, dürften diese Stoffe für die Mumien bestimmt gewesen sein, die ja neu eingewickelt werden mußten, wenn man sie aus ihren alten Särgen nahm und die Juwelen an ihnen entfernte.

Auch in den Königsgräbern selbst gibt es Graffiti, leider oft schwer zu lesen und z. T. schlecht publiziert (wenn überhaupt). Interessant ist v. a. das 2. Graffito im Grab des Haremhab aus einem Jahr 6, II. 3 bुt, $12^{67}$ : Hier wird möglicherweise berichtet, daß an diesem Tag das Begräbnis des Haremhab ,weggebracht" worden ist $\left(f_{3} j\right)$. Unglücklicherweise war die Schrift so schwach, daß Gardiner, der dieses Graffito abgeschrieben hat, sich über die Umschrift nicht ganz im klaren war: Es wäre statt $f_{3} j$, wegbringen“ auch $\check{s} n j^{\prime}$, ,inspizieren“ möglich. Die Sache ist leider nicht mehr nachprüfbar, das Graffito scheint heute verschwunden zu sein. Der Name dessen, der diese Aktion anordnete, ist nicht erhalten, aber den Titeln zufolge $\left(\underline{t}^{2} t j+m r{ }^{2} \tilde{s}^{c}\right)$ kann es sich nur um Pianch oder Herihor gehandelt haben. Falls $f_{3 j} j$ zu lesen wäre, hätte man also einen deutlichen Hinweis darauf, daß der Grabinhalt amtlicherseits entfernt wurde.

\footnotetext{
${ }^{62}$ Im folgenden nur nach Nr. zitiert. Publiziert sind die Nr. 1-1059 bei W. Spiegelberg, op. cit. (Anm. 34), 1060-1405 bei J. Černý, Graffiti hiéroglyphiques et hiératiques de la nécropole thébaine, DFIFAO 9, Kairo 1956, 1578-3973 bei J. Černý/A. A. Sa dek, Graffiti de la montagne thébaine, Collection scientifique, Bd. I-IV, Kairo 1970ff.

${ }^{63}$ Bei dem es sich sicher nur um eine einzige Person handelt, nicht um drei verschiedene, wie dies A. Niwiński vorgeschlagen hat, s. GM 139, 1994, 35-40.

${ }^{64}$ Ausgerechnet dieses Graffito im Wadi Gabbanāt el-Gurūd befindet sich aber nahe des „Grabes der drei Prinzessinnen" (s. H.E. Winlock, The Treasure of Three Egyptian Princesses, New York 1948), das in der Antike nie geöffnet, also offenbar übersehen wurde.

${ }^{65}$ Im Tal der Könige, nahe dem Grab Sethos II.; Jahr 20.

${ }^{66}$ Op. cit., p. $230-1$.

${ }^{67}$ Reeves, op. cit., pl. VI; p. 77-9.
} 
10. Die zahlreichen Graffiti des Butehamun sind keineswegs auf das Tal der Könige begrenzt, sondern auch an vielen anderen Orten der thebanischen Nekropole zu finden ${ }^{68}$. Wenn sie, wie ich vermute, etwas mit der systematischen Suche nach Gräbern zu tun haben, hieße das, nicht nur die Königsgräber, sondern auch viele andere seien damals zur „Wiederverwertung“ freigegeben worden. Dafür gibt es in der Tat Anzeichen, die kürzlich J. Taylor kurz zusammengefaßt dargestellt hat ${ }^{69}$ : Es ist längst bekannt, daß nach dem Neuen Reich die systematische Wiederbelegung von älteren Gräbern beginnt, es werden keine neuen Felsgräber mehr ausgeschachtet. Zweitens ist die Zahl der Särge aus dem Neuen Reich ausgesprochen gering, vergleicht man sie mit der der folgenden Epochen. Ein Teil der Särge ist zweifellos wiederverwertet worden, andere Särge, v. a. diejenigen, die vergoldet waren und Einlegearbeiten hatten, dürften vielfach zerstört worden sein. Im Vergleich zu anderen, weniger wertvollen, Grabbeigaben gibt es jedenfalls außerordentlich wenige Särge. Man wird also davon auszugehen haben, daß auch viele Privatgräber nach dem Neuen Reich systematisch von ihren Wertsachen befreit worden sind, ihre Rohmaterialien wiederverwertet und die Gräber, jedenfalls z. T., neu belegt wurden.

11. Archäologisch ist kaum jemals festzustellen, was genau passiert ist, da ja fast alle Gräber im Verlauf der Zeit vielfach durchwühlt worden sind und bei den wenigen halbwegs intakt gefundenen die alten Grabungspublikationen unzureichend sind. Immerhin kann man auf einen Fall verweisen, der mustergültig dokumentiert ist, nämlich das Grab der Königin Meryetamun aus der 18. Dynastie ${ }^{70}$. Dieses Grab ist gründlich von allen wertvollen Materialien befreit worden: Das Goldblech, mit dem die inneren Särge überzogen waren, die Vergoldung der anderen Holzgegenstände, die Glasflußeinlagen, die an der Mumie befindlichen Juwelen etc. Danach hat man die Mumie neu eingewickelt, die Särge neu gestrichen (als Ersatz des Goldblechs und der Einlagen) und das Grab aufgeräumt ${ }^{71}$.

Wie nun ein hieratischer Vermerk auf der Mumienhülle besagt ${ }^{72}$, ist das Grab im Jahr 19 (entweder auf Pajnedjem I. oder Smendes bezogen), ,inspiziert" worden. Winlock nimmt an, daß es kurz vorher beraubt worden ist und das Datum sich auf die amtliche Restaurierung bezieht. Das ist aber ziemlich unwahrscheinlich: Das Begräbnis enthielt ursprünglich einen Kastensarg oder Schrein aus Holz und 3 (z. T. riesige) anthropomorphe Holzsärge. Der Schrein und der äußere Sarg sind entfernt worden, nachdem sie vorher sorgfältig an den Verzapfungen der Fugen aufgesägt worden sind, wie Winlock beschreibt, nicht etwa aufgebrochen! Die sich so ergebenden Planken wurden offenbar von den Beamten mitgenommen - das nimmt auch Winlock $a^{73}$ - nicht von den Dieben (da ja die beiden inneren Särge unversehrt zurückgelassen wurden). Goldblech und Einlagen der inneren Särge wurden nun nicht etwa abgerissen und herausgebrochen, sondern, wie bei den entsprechenden Särgen aus der frühen 18. Dynastie aus der Cachette von Deir el-Bahari, „painstakingly removed“774. Das alles spricht keineswegs für die Tätigkeit von Dieben, sondern dafür, daß das Grab von offizieller Seite entleert worden ist. Winlock geht wohl nur deshalb ohne weiteres von einer

\footnotetext{
${ }^{68}$ S. die Zusammenstellung von A. Niwiński, SAK 11, 1984, 150, n. 55.

${ }^{69}$ In dem in Anm. 49 zitierten Aufsatz, p. 189-90.

${ }^{70}$ H. H. Winlock, The Tomb of Queen Meryet-Amūn at Thebes, PMMA 6, New York 1932.

${ }^{71}$ Ibid., p. $40 \mathrm{ff}$.

${ }^{72}$ Ibid., p. 51 ; pl. XLI, B.

${ }^{73}$ Ibid., p. 41, n. 4.

${ }^{74}$ Ibid., p. 41 , n. 5.
} 
Beraubung aus, weil damals noch niemand auf die Idee gekommen war, die „Räuber“ könnten von Amts wegen bestellt sein.

Es ist bemerkenswert, daß nur die beiden äußeren Särge der Meryetamun als Materialien wiederverwertet werden, die beiden inneren aber nicht: In der 21. Dynastie, als sich dies abspielte, hat man immer nur 2 Särge. Die Wiederverwertung von Holz aus alten Begräbnissen ist übrigens auch sonst bezeugt, nicht nur für Särge: J. Taylor hat in seinem bereits erwähnten Artikel z. B. darauf verwiesen, daß königliche Uschebtis in Osirisfiguren umgearbeitet worden $\operatorname{sind}^{75}$.

12. Bei diesen Vorgängen sind natürlich die Nekropolenarbeiter von großer Wichtigkeit, denn sie waren es ja zweifellos, die die Gräber zu öffnen und auszuräumen hatten; zumindest waren sie regelmäßig daran beteiligt, wie die Namen in den Graffiti und „dockets“ zeigen ${ }^{76}$.

In diesem Zusammenhang ist es interessant, daß zwischen dem General Pianch und den Nekropolenarbeitern, besonders dem Schreiber Thutmose und seinem Sohn Butehamun, ganz außerordentlich enge Beziehungen bestehen, die durch das Konvolut der Late Ramesside Letters bezeugt sind (vgl. oben, \7-8). Der Schreiber Thutmose etwa begleitet den General auf seinem Feldzug nach Süden, und zwar als Berater, wie ausdrücklich gesagt ${ }^{77}$, aber sicher nicht in militärischen Dingen, von denen er nichts versteht ${ }^{78}$. Er und sein Sohn Butehamun, der ein sehr eindrucksvolles Haus (oder Amt) in Medinet Habu hat, unweit der Residenz des Hohenpriesters, erledigen dauernd Aufträge für ihn, auch solche, die offensichtlich nichts mit der Arbeit in der Nekropole zu tun haben.

Umgekehrt führen die Nekropolenarbeiter nicht nur willig (und ängstlich) alle Befehle des Pianch aus, sie werden auch dafür belohnt: Aus einem Brief ${ }^{79}$ erfährt man z. B., daß er ihnen 5 Sklavinnen schenkt, wobei er betont, daß sie allen Arbeitern gehören, den einfachen und den Vorarbeitern, und sie sich nicht darum streiten sollten. Es ist sicher sehr ungewöhnlich und auffallend, daß Pianch, der ja zu dieser Zeit praktisch der unumschränkte Herr von Oberägypten war, auf so vertrautem Fuß mit den Nekropolenarbeitern steht.

Am bezeichnendsten dafür ist ein Fall, wo Pianch dem Schreiber Thutmose und einem anderen Vertrauten die briefliche Anweisung gibt ${ }^{80}$, zwei Polizisten, die über irgend eine nicht näher bezeichnete Sache zuviel geredet haben, in das Haus des Generals zu schaffen und dort zu vernehmen, und zwar in Anwesenheit seiner Tochter Nedjemet ${ }^{81}$, die offenbar sein besonderes Vertrauen hat und gleichfalls brieflich instruiert wird ${ }^{82}$. Danach sollen sie die beiden Polizisten erschlagen, in zwei Körbe stecken und im Nil versenken, und zwar „ohne daß irgend jemand im ganzen Land etwas davon erfährt". Das ist ein Auftrag, der ganz deutlich nicht in das eigentliche Ressort der Arbeiter fällt ${ }^{83}$.

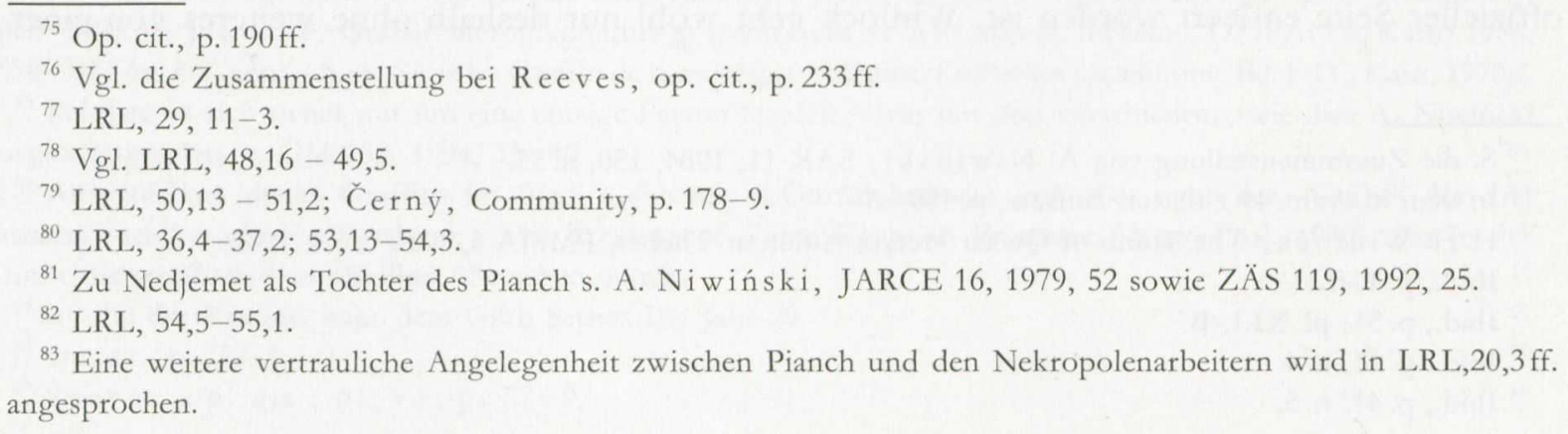


Wie kann man sich nun dieses besondere Verhältnis zu den Nekropolenarbeitern erklären? Černý hatte angenommen ${ }^{84}$, Pianch habe die Arbeiter für seine Armee rekrutiert, jedenfalls zum Teil, und der Rest sei dann vor der drohenden Konskription geflohen. Er verweist dafür auf einige Stellen in den LRL, wo Thutmose seinen Sohn anweist, sich um Soldaten zu kümmern (LRL, 8,6-8; 10,11-2). Es ist aber keineswegs zwingend, daß mit diesen Soldaten $\left(n 3 r_{n} w m^{\circ}\right)$ die Nekropolenarbeiter gemeint sind, im Gegenteil, das ist sehr unwahrscheinlich, da sie in der sonstigen Korrespondenz des Thutmose nie so genannt werden. Es dürfte sich eher um Soldaten des Pianch handeln, die zum Schutz der Nekropolenarbeiter abgestellt waren.

Daß Thutmose selbst keinerlei militärische Aufgaben wahrnahm, als er den Pianch nach Nubien begleitete, wird klar gesagt (s.o.). Auch die beiden anderen Nekropolenarbeiter, die ihn zeitweise begleiten und denen Butehamun dringend ans Herz legt, sich um seinen kranken Vater zu kümmern (LRL, 16,7-9), sind wohl kaum als Kombattanten unterwegs: Sie werden kurz darauf von Pianch als Boten nach Theben zurückgeschickt ${ }^{85}$, haben also eher Kurierdienste zu versehen. Sie können kaum als Beleg dafür dienen, daß man die Nekropolenarbeiter in Soldaten verwandelt hatte.

Auch die angebliche Gestellungsflucht ist mehr als unsicher: Wenn ein Teil der (ehemaligen?) Nekropolenarbeiter auf dem thebanischen Westufer wohnt (LRL, 23,12-3; 45,7-8), kann das die unterschiedlichsten Gründe haben, sie müssen keineswegs geflohen sein. Schließlich wurden sie damals für ihre eigentliche Arbeit nicht mehr gebraucht, es wurden keine neuen Königsgräber mehr angelegt, und ihre neue Aufgabe wird ja gerade in diesem Brief erst angedeutet.

Wenn es sich bei dieser Aufgabe aber nur mehr um die Restauration bereits geplünderter Gräber handelte, hätte Pianch, der damals Krieg führte und zweifellos in einer politisch heiklen Lage war, darauf solchen Wert gelegt? Die Sache läßt sich nur so erklären, daß er irgendein wichtiges Vorhaben hatte, für die er die Arbeiter als Fachleute brauchte, und dabei kann es sich eigentlich nur um materielle Nutzung der alten Gräber handeln.

13. Daß der Nekropolenschreiber Butehamun eine Schlüsselrolle bei der Öffnung und Ausräumung der Nekropole hatte, wird schließlich auch durch einige ungewöhnliche Titel (bzw. Epitheta) bestätigt, die er in hieroglyphischen Inschriften (natürlich nicht in der Korrespondenz) führt:

Auf seinem Sarg in Brüssel (E. 5288) ${ }^{86}$ heißt er u.a.: wn(n) ${ }^{c} 3 w j m$ r'-sţ $3 w$ „Öffner der Türen in der Nekropole“, daneben auch $m r n f r w$ pr $\underline{d} t$. Auf dem Sargensemble in Turin $(2236-7)^{87}$

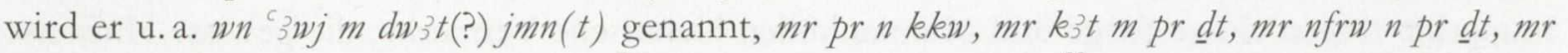

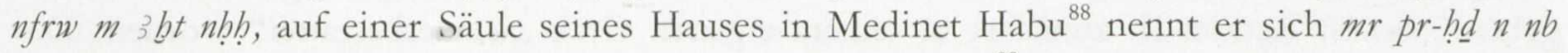
$t_{5}$ wj $m$ st $m_{3}^{3} t$, und sein Vater heißt auf einer anderen Säule ${ }^{89} m r k 3 t m$ pr $\underline{d} t$.

Das alles ergibt nur einen Sinn, wenn beide an der Ausräumung der alten Gräber tätig waren, was ja durch die „Türöffner-Titel“ des Butehamun geradezu direkt gesagt wird. In

\footnotetext{
${ }^{84}$ Community, p. 379-80; gefolgt von Valbelle, Les ouvriers, p. 225 und M. Bierbrier, The Tomb-Builders of the Pharaohs, London 1982, 119-121.

${ }^{85}$ LRL, 45,8-10.

${ }^{86}$ S. L. Speleers, Recueil des inscriptions égyptiennes des Musées Royaux du Cinquantenaire à Bruxelles, Brüssel 1923, p. 76-7 (288) und A. Niwiński, 21 st Dynasty Coffins from Thebes, Theben V, Mainz 1988, p. 112 (47).

${ }^{87} \mathrm{Vgl}$. E. Schiaparelli, Il libro dei funerali, I, Rom/Turin/Florenz 1882, p. 14-5; Niwiński, op. cit., p. $172-3$ (385). Vgl. auch $\mathrm{PMI}^{2}, 741$.

${ }^{88}$ Kitchen, Ram. Inscr, VII, 402,5.

${ }^{89}$ Ibid., 402,13-4.
} 
diesem Fall ist auch sein merkwürdiger Titel als „Schatzmeister" erklärlich" ${ }^{90}$ Die Gräber stellten ja praktisch eine Art Schatzkammer dar, für die Butehamun in besonderer Weise verantwortlich war.

14. Will man die Vorgänge um die Königsgräber und -mumien richtig verstehen, ist schließlich noch etwas zu bedenken, und das ist die zeitliche Ausdehnung der Vorgänge. Wie den hieratischen Vermerken auf den Mumien und Särgen zu entnehmen ist, haben sich die Bergungsarbeiten über mindestens 110 Jahre (falls die letzte Umbettung im 10. Jahr Siamuns stattfand), vielleicht sogar über etwa 140 Jahre erstreckt (falls sie nach dem Jahr 11 bzw. 13. Schoschenks I. anzusetzen ist) ${ }^{91}$. Geht man von der Plünderung der Gräber durch Räuberbanden aus, muß man zwei Möglichkeiten unterscheiden: Entweder die Gräber waren schon am Ende des Neuen Reiches ausgeraubt, gleichgültig, ob das über einen längeren Zeitraum geschah oder schlagartig, wie Aldred meint, oder aber die Räubereien setzten sich die 21. Dynastie über fort, wie es das eingangs geschilderte Szenario voraussetzt, wo die Priester mit den Mumien auf der Flucht vor Räuberbanden $\operatorname{sind}^{92}$.

Im ersten Fall hieße das, die Aufräumungsarbeiten, die bloße Bergung der Überreste, hätten weit über 100 Jahre gedauert, und das ist kaum vorstellbar, vor allem, da den noch in der Neuzeit vorhandenen Überbleibseln der ursprünglichen Grabausstattung zu entnehmen ist, daß man nicht unbedingt sehr langsam und gründlich vorgegangen ist.

Die zweite Möglichkeit, daß nämlich die Überreste unter der permanenten Gefahr weiterer Diebstähle geborgen wurden, ist aus den bereits erwähnten Gründen ( $(4)$ abzulehnen: Es würde bedeuten, daß die Diebe sozusagen bei Nacht tätig waren und die Priester und Beamten dann am Tag die traurigen Reste einsammelten. Der Schauplatz lag aber ganz nahe der Residenz des Herrschers von Oberägypten und konnte mit einer Handvoll Leuten leicht bewacht werden. Derartige Vorgänge, zumal über einen längeren Zeitraum, sind sicher auszuschließen.

Umgekehrt macht die lange zeitliche Ausdehnung dieser Vorgänge aber durchaus Sinn: Wenn nämlich der Reichtum der Königsgräber (und der der anderen Gräber natürlich gleichfalls) von Amts wegen genutzt wurde, dann stellte das Tal eine leicht zu sichernde Schatzkammer dar, und es wäre wenig sinnvoll gewesen, die Gräber auf einmal zu leeren.

15. Wie diese Dinge im einzelnen verlaufen sind, läßt sich natürlich nicht mehr rekonstruieren. Immerhin tragen einige Särge und Mumienhüllen hieratische Vermerke, die gewisse Hinweise geben $^{93}$. So ist Ramses II. zunächst in seinem eigenen Grab „wiederbestattet “ worden: Das war unter Herihor im Jahr 6, und man darf annehmen, daß damals dem Grab seine hauptsächlichen Schätze entnommen worden sind. Dann ist Ramses unter Pajnedjem im Jahr 15 ins Grab seines Vaters Sethos I. verlegt worden: Man könnte sich vorstellen, daß damals das Grab völlig entleert worden ist und man Sarg und Mumie praktischerweise in ein anderes Grab brachte, damit das nunmehr leere nicht länger bewacht zu werden brauchte. Im Jahr 10 des Königs Siamun wird dann Ramses zusammen mit seinem Vater Sethos I. und seinem Großvater Ramses I. wiederum verlegt, nachdem man dafür ein zustimmendes Orakel

\footnotetext{
${ }^{90}$ Das $n b$ t3wj darin dürfte sich auf Amun beziehen, kaum auf den König.

${ }^{91} \mathrm{Zu}$ diesen Alternativen s. u., Anm. 94-5.

${ }_{92}$ Vgl. in diesem Sinn auch z. B. Kitchen, Third Interm. Period, $\int 233$.

${ }^{93} \mathrm{Zu}$ den einzelnen Vermerken bzw. „dockets“ s. die Zusammenstellung bei Kitchen, Third Interm. Period, $\int 379$ ff. und Reeves, Valley, Kap. 11 mit den jeweiligen Verweisen.
} 
der Göttin Mut eingeholt hatte, und zwar in das Grab der Inhapi, das möglicherweise identisch ist mit der Cachette von Deir el-Bahari, also mit ihrem endgültigen Ruheplatz ${ }^{94}$. Sollte es das nicht sein, wie jetzt Reeves annimmt, wären alle drei ein weiteres Mal zu Beginn der 22. Dynastie in eben diese Cachette verlegt worden ${ }^{95}$.

Was auch immer im einzelnen passiert sein mag, eine bestimmte Tendenz ist deutlich greifbar: Im Lauf der Zeit werden die Enteignungsmaßnahmen immer gründlicher, immer mehr Dinge werden darin einbezogen: Z.B. werden in der Mitte bzw. am Ende der 21. Dynastie auch Särge, die nur einen Goldüberzug hatten, bearbeitet, und dieser Überzug wird abgehackt oder abgeschabt und der Sarg dann oft gelb übermalt ${ }^{96}$. Daß dies nicht von Anfang an so gehandhabt wurde, läßt sich an Folgendem erkennen: Wie erwähnt, diente die Cachette von Deir el-Bahari auch (und zunächst) als Sammelgrab der Hohenpriesterfamilie der 21. Dynastie, und deren Begräbnisse haben zu Beginn der 21. Dynastie selbst noch derartig vergoldete Holzsärge; eben diese Särge werden aber später gleichfalls von ihrem Überzug befreit $^{97}$ (obwohl ja immer noch dieselbe Familie regiert; es sind die Särge der eigenen unmittelbaren Vorfahren!). Man könnte nun einwenden, gerade diese Tatsache, daß die Särge der 21. Dynastie selbst einbezogen wurden, sei ein Beweis dafür, daß hier Grabräuber am Werk waren, und dies ist in der Tat früher auch durchgehend angenommen worden ${ }^{98}$. Dagegen spricht aber, daß bei diesen Abarbeitungen generell Götterfiguren, religiöse Symbole und z. T. auch die Namensaufschriften geschont worden sind. Zu unterstellen, wie das öfter getan worden ist ${ }^{99}$, hier seien eben sehr abergläubische Räuber am Werk gewesen, ist doch sehr unwahrscheinlich. Diejenigen, die die religiös essentiellen Schmuckembleme unangetastet ließen, können nur Priester oder Beamte gewesen sein. Übrigens hat man auch deutliche Spuren dieser Abarbeitungen entdeckt, und zwar im Schacht des Grabes Ramses' XI. ${ }^{100}$, und es wäre schwer vorstellbar, daß Räuber die Särge aus den Gräbern zu einem weiter entfernten Ort brachten, um dann erst ihren Überzug zu entfernen. Wenn überhaupt, wäre das doch an Ort und Stelle geschehen. Diese Abarbeitungen können also nur das Werk amtlich befugter Personen gewesen sein.

16. Es gibt also eine Reihe von Argumenten, die dagegen sprechen, daß die Gräber im Tal der Könige von Räuberbanden geplündert worden sind:

${ }^{94}$ Wie das Černý (im Anschluß an Winlock) angenommen hat aufgrund der identischen Daten und (z. T.) Personen in den „dockets“ auf den Särgen Sethos' I. und Ramses’ II., in denen ihre Überführung in das Grab der Inhapi berichtet wird, und dem Wandgraffito der Cachette anläßlich der Bestattung Pajnedjems II., s. JEA 32, 1946, $24 \mathrm{ff}$. Wenn Černý recht hat, fand die letzte bekannte Umbettung im Jahr 10 Siamuns statt, denn die jüngeren Daten aus der Cachette betreffen alle nur noch Primärbestattungen.

${ }^{95}$ Gestützt auf die relative Lage der einzelnen Särge, hat Reeves sehr beachtliche Argumente dafür vorgebracht, daß die Cachette nicht mit dem Grab der Inhapi identisch ist, s. Valley, p. $183 \mathrm{ff}$. Ihm zufolge sind die letzten Umbettungen (u. a. der Särge von Ramses I. und II. und Sethos I.) nach den letzten Primärbestattungen, die aus dem Jahr 11 (und 13?) Schoschenks I. stammen, vorgenommen worden. Zumindest dieser letzte Punkt ist aber nicht unbedingt zwingend. Außerdem ist Reeves' Hinweis, die Identität der Daten und Personen, auf die sich Černý gestützt hatte, sei rein zufällig, doch wenig befriedigend. Keine der Alternativen scheint z. Zt. wirklich überzeugend.

${ }^{96}$ S. Taylor, op. cit. (Anm. 49), p. 187-8.

${ }^{97}$ S. die Übersicht bei Reeves, Valley, p. 212-5.

${ }^{98}$ S. z. B. G. Daressy, Cercueils des cachettes royales (CG), Kairo 1909, p. 40; 50; 65 u.ö.

${ }^{99}$ Z.B. Maspero, Momies royales, p. 569; Niwiński, Coffins, p. 40.

${ }^{100}$ S. Taylor, op. cit., p. 188 mit n. 15 (p. 203); Reeves, Valley, p. 121-2. 
Bis zum Ende des Neuen Reiches ist kein gravierender Zwischenfall bekannt geworden, in den Grabräuperpapyri werden diese Gräber nicht erwähnt. Auch für die folgende Zeit sind Diebstähle in großem Stil im Tal unwahrscheinlich, sie wären für kleine Banden technisch schlecht durchführbar gewesen, und die Beute kaum absetzbar.

Natürlich ist Aldreds These der Plünderung durch Panehsis Armee möglich, aber es fehlt jeder konkrete Hinweis dafür.

Dagegen gibt es zahlreiche Gründe, die dafür sprechen, daß die Gräber staatlicherseits entleert worden sind:

Zunächst ganz allgemein die politisch-ökonomische Situation: Der Wegfall der nubischen Kolonien (und damit der Goldminen) und der asiatischen Besitzungen, die Schwierigkeiten auch des friedlichen Handels mit Vorderasien, die ja in der Geschichte des Wenamun lebhaft geschildert werden.

Im besonderen dann die Hinweise, die der Brief der Nekropolenarbeiter an den Pianch enthält, und überhaupt das merkwürdig intime Verhältnis des Pianch zu den Nekropolenarbeitern, das darauf schließen läßt, daß sie für ihn von großer Wichtigkeit waren, obwohl ja ihre eigentliche Aufgabe beendet war; ferner die große Anzahl der Graffiti aus dieser Zeit, die darauf hindeuten, daß systematisch nach Gräbern gesucht wurde, was in einigen Fällen auch mehr oder weniger ausdrücklich gesagt wird; der archäologische Befund an einigen Särgen, die sorgfältig demontiert und deren Goldbeschlag vorsichtig abgenommen worden ist, und an anderen, wo die Vergoldung unter Schonung der religiösen Symbole und der Inschriften entfernt wurde; schließlich die zeitliche Ausdehnung der Aktionen, die bei einer planmäßigen Verwertung sinnvoll und zu erwarten wäre, nicht dagegen bei Aufräumungsarbeiten.

Dennoch ist es natürlich nicht so, daß man bei der Frage, wer die Königsgräber ausgeräumt hat, notwendigerweise vor einem radikalen Entweder-Oder steht. Es wäre etwa durchaus vorstellbar, daß zunächst - wie Aldred es vermutet hat - die Armee des Panehsi auf ihrem Rückzug ein oder mehrere Gräber plünderte, und dann, als das Tabu einmal gebrochen war, auch die restlichen Gräber planmäßig geleert wurden. Ebensowenig ist ausgeschlossen, daß auch der eine oder andere „private“ Diebstahl bzw. Übergriff vorkam; das ist sogar sehr wahrscheinlich. Zumindest in der Masse der Fälle dürfte aber die Administration für die Ausräumung der Gräber verantwortlich gewesen sein.

17. $\mathrm{Ob}$ Aldreds Vermutung über die räuberischen Aktivitäten von Panehsis Armee nun zutrifft oder nicht, zumindest ein Aspekt daran sollte zu beachten sein: Gegen Ende des Neuen Reiches bestehen die Truppen auf ägyptischem Boden in starkem Maße, wenn nicht sogar vorwiegend, aus ausländischen (libyschen und nubischen) Verbänden, und es liegt nahe, daß bei diesen Soldaten viel geringere emotionale Handlungshemmnisse zu erwarten sind, wenn in ihrer Nähe in der Wüste ungeheure Schätze vorhanden sind, und zwar aufgrund religiöser und traditioneller Vorstellungen, die diese Soldaten nicht teilen.

Es ist oben dargelegt worden, daß die Annahme, die Staatsmacht sei nicht mehr in der Lage gewesen, das Tal der Könige gegen Räuberbanden zu schützen, ziemlich unwahrscheinlich ist. Es war aber dennoch durchaus Grund zur Beunruhigung vorhanden, wenn wichtige Teile der Staatsmacht selbst eine potentielle Gefahr darstellten. Dann wäre es wirklich ratsam gewesen, diese Schätze allmählich unauffällig zu entfernen.

Dennoch bewegt man sich mit solchen Spekulationen natürlich auf sehr unsicherem Boden, denn über die wirkliche Rolle der $M \check{s} w s$, Rbw, b ${ }_{3} s t j w$ (etc.) in Theben seit dem Ende der 20. Dynastie wissen wir so gut wie nichts. Zudem hängt dieses Problem mit einem anderen 
zusammen, über das wir gleichfalls kaum Informationen haben: Wer die neuen Machthaber Ägyptens in der 21. Dynastie eigentlich waren. Es gibt inzwischen Grund zu der Annahme, daß die Herrschaft der Libyer über Ägypten nicht erst in der 22. Dynastie einsetzte, sondern schon am Ende des Neuen Reiches begann, mit der 21. Dynastie ${ }^{101}$. In diesem Fall wäre es um so verständlicher, daß man nicht davor zurückschreckte, sich die Schätze der alten Gräber anzueignen, die nicht den eigenen Vorfahren gehörten.

18. Welcher Herkunft die neuen Herrscher auch gewesen sein mögen, die Räumung der Königsgräber, noch dazu so radikal durchgeführt, war ein Unternehmen, durch das man von der bisherigen Haltung gegenüber den verstorbenen Königen grundlegend abwich, und das weist in jedem Fall auf eine gänzlich andere Einstellung dieser Zeit zum Königtum hin. In der Tat gibt es für diese veränderte Einstellung ja auch sonst Anzeichen:

Im thebanischen „Gottesstaat“ der 21. Dynastie ist bekanntlich Amun der eigentliche König, und diejenigen Menschen, die in dieser Zeit als Könige fungieren oder sich doch königliche Attribute zulegen, geben in ihrer Titulatur offen zu verstehen, daß sie sich selbst nicht als wirkliche Könige betrachten. Für die Hohenpriester des Amun, die königliche Namen und Attribute tragen (Herihor, Painedjem I., Mencheperre), ist das ohnehin klar und wird durch die Aufnahme des Hohenpriestertitels in die Königstitulatur (sogar in Kartusche geschrieben) ganz deutlich ${ }^{102}$. Für die Könige der 21. Dynastie in Tanis gilt das nicht im gleichen Maße, aber auch hier findet man bei Psusennes I. des öfteren dieselbe Erscheinung $^{103}$, ebenso bei Amenemope ${ }^{104}$ und bei Psusennes II., wenn er denn mit dem Hohenpriester identisch sein sollte. Daß sie nicht bei allen Königen nachzuweisen ist, dürfte ein Zufall der Überlieferung sein, sind diese doch (von Siamun abgesehen) weit weniger gut bezeugt.

Auch in den Texten und Inschriften der Zeit kommt die Königsrolle des Amun klar zum Ausdruck, wenn der Gottesname in Positionen einrückt, wo eigentlich ein Königsname oder eine Königsbezeichnung zu erwarten wäre ${ }^{105}$ und dabei z. T. auch die Form einer Königstitulatur annimmt ${ }^{106}$. Als Mittel der königlichen Herrschaft des Gottes diente v.a. das Orakelwesen, und in der späteren 21. Dynastie zumindest hat sich die Sache so weit entwickelt, daß der Gott

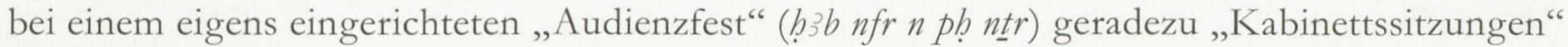
auf diese Weise abhält ${ }^{107}$.

Wenn also in dieser Zeit Amun als der eigentliche König betrachtet wird, ist es nicht so erstaunlich, daß man auch gegenüber verstorbenen (menschlichen) Königen eine andere Haltung einnimmt. Man vergleiche dazu auch Wenamun 2,53 ff. ${ }^{108}$, wo Wenamun den Fürsten

\footnotetext{
${ }^{101}$ S. Biblische Notizen 71, 1994, 78-97.

${ }^{102}$ Auch für Painedjem I. in einer Inschrift im Grab Ramses’ XI. belegt.

${ }^{103}$ S. Montet, Tanis, II, p. 98, Fig. 39 und 40; M.-A. Bonhême, Les noms royaux dans l'Egypte de la Troisième Période Intermédiaire, BdE 98, 1987, p. 73-4.

${ }^{104}$ Bonhême, op. cit., p. 81.

${ }^{105}$ Z. B. in der Formel djw $m$ ḅzwt $n$ nb ntrw Jmn (statt djw $m$ ḅzwt nt br njswt) auf einer Statue des Herihor, s. Kitchen, Ram. Inscr., VI, 843,14.

${ }^{106}$ Vgl. dazu M. Römer, Gottes- und Priesterherrschaft in Ägypten am Ende des Neuen Reiches, ÄUAT 21, 1994, J 107-9. Im ersten Teil dieser Arbeit wird der ganze Fragenkomplex von königlichen Priestern und priesterlichen Königen sowie Göttern in der Rolle des Königs im Detail behandelt.

${ }^{107}$ S. J.-M. Kruchten, BSFE 103, 1985, 6ff. (bes. 22-3); id., Le grand texte oraculaire de Djéhoutymose, MRE 5, 1986, 335.

${ }^{108}$ LESt, p. 72.
} 
von Byblos darauf hinweist, daß (der frühere Pharao) $H^{c} j-m-W_{3} s t^{109}$ ein Mensch war und menschliche Boten schickte, nun aber der Götterkönig Amun-Re derjenige ist, der einen göttlichen Boten (den „Amun des Weges“) sendet ${ }^{110}$. Von der „Göttlichkeit des Pharao“ ist hier in keiner Weise mehr die Rede.

Bei dieser Einstellung wäre es durchaus logisch, nun auch (u.a.) die Edelmetalle, die in den Gräbern der nicht länger als Götter angesehenen alten Könige lagerten, dem wirklichen König, dem Gott, zur Verfügung zu stellen. Möglicherweise gehört sogar noch eine Inschrift Osorkons I. aus Bubastis ${ }^{111}$ in diesen Zusammenhang, worin verschiedenen Göttern zahlreiche Tempelgerätschaften überwiesen werden, die geradezu gigantische Mengen an Edelmetall enthalten ${ }^{112}$.

Wie dem auch sei, in jedem Fall dürfte die in der 21. Dynastie zu beobachtende Übertragung der wahren Königsherrschaft auf den Götterkönig der ökonomisch ohnehin wünschenswerten Ausbeutung der materiellen Ressourcen der alten Gräber eine gewisse ideologische Stütze gegeben haben.

\footnotetext{
${ }^{109}$ Ramses IX. oder - wahrscheinlicher - Ramses XI., sicher nicht der gleichnamige Wezir. Die Geschichte des Wenamun spielt in einer Zeit, wo Ramses XI. schon tot war, nicht in der Wḥm-mswt-Ära, s. ZÄS 119, 1992 , $25-6$.

${ }^{110}$ S. dazu auch Gardiner, Egypt, p. 311, n. 3.

${ }^{111}$ Naville, Bubastis, pl. LI, G.

${ }^{112}$ Und die Kitchen, Third Interm. Period, $\int 262$, mit dem Feldzug Schoschenks I. nach Palästina in Verbindung gebracht hat.
} 